\title{
Posting Patterns of Students' Social Presence, Cognitive Presence, and Teaching Presence in Online Learning
}

\author{
Selcan Kilis \\ Giresun University \\ Zahide Yildirim \\ Middle East Technical University
}

\begin{abstract}
Using the Community of Inquiry framework, this case study probes the posting patterns of students' social presence, cognitive presence, and teaching presence in an online learning setting. Using purposive sampling, qualitative data were collected from 91 students in the Department of Medical Documentary and Secretary, a fully online associate degree program at a well-known public university. Students participated in six online asynchronous discussion activities on Moodle. The data were analyzed through descriptive and deductive transcript analysis. The findings revealed students' posting behaviors of social presence, cognitive presence, and teaching presence were at a substantially high level, and could be enhanced during treatment fairly significantly. The most important points behind a high level of social presence and cognitive presence were found to be the topics based on real-life cases and scenarios and reflective course activities. The findings further indicated that the difficulty caused by large class size in online discussion could be resolved.
\end{abstract}

Keywords: social presence, cognitive presence, teaching presence, online asynchronous discussion, online learning

Kilis, S., \& Yildirim, Z. (2019). Posting patterns of students' social presence, cognitive presence, and teaching presence in online learning. Online Learning, 23(2), 179-195. doi:10.24059/olj.v23i2.1460

\section{Posting Patterns of Students' Social Presence, Cognitive Presence, and Teaching Presence in Online Learning}

Aimed specifically at online and blended learning settings, one instructional development of significance is the Community of Inquiry (CoI) framework, developed by Garrison, Anderson, and Archer (2000). CoI provides a coherent perspective to enhance the complex dynamics of collaborative online learning environments (Garrison \& Akyol, 2015). It aims to facilitate greater learning by constituting a community with an emphasis on the processes of instructional conversations likely to lead to epistemic engagement (Shea \& Bidjerano, 2009). The CoI framework also articulates the behaviors and processes required to nurture knowledge construction through the cultivation of various forms of presence. It explains any type of online educational experience as the intersection of three presence types: social presence, teaching presence, and cognitive presence (Swan, Garrison, \& Richardson, 2009). Social presence is the mediating variable between teaching presence and cognitive presence (Garrison, Cleveland-Innes, \& Fung, 2010). Social presence encompasses three constructs: affective/personal responses, open communication, and cohesive responses. Affective/personal 
responses refer to emotional expression, use of humor, self-disclosure, and so on. Open communication includes continuing a thread, quoting from others' messages, referring explicitly to others' messages, asking questions, complimenting or expressing appreciation, expressing agreement, and so on. Cohesive responses refer to vocatives, referring to the learning group using inclusive pronouns, common salutations, and so on. (Rourke, Anderson, Garrison, \& Archer, 2001).

Cognitive presence reflects the learning and inquiry process and is operationalized in the practical inquiry (PI) model as four phases: triggering event, exploration, integration, and resolution (Garrison et al., 2000). A triggering event is considered the starting phase and includes recognizing the problem, puzzlement facilitating curiosity, motivation, and a problembased approach. Exploration is inquisitive and includes the searching for relevant information about the problem, exchanging information, exploring content collaboratively, brainstorming, making suggestions for consideration, and proposing a conclusion. Integration tends to be more tentative and includes convergence among community members through the connection of ideas and synthesis of information, and sustained critical reflection. Resolution includes testing knowledge through vicariously applying it to real-life problems and defending solutions (Garrison, Anderson, \& Archer, 2000). According to Garrison and Anderson (2003), cognitive presence is central to successful higher education.

Teaching presence includes design and organization, facilitation of discourse, and direct instruction (Anderson, Rourke, Garrison, \& Archer, 2001). Design and organization refers to activities in which teachers engage to design and organize a course or learning environment, such as determining curriculum, designing or selecting instructional methods, establishing time parameters, utilizing mediums effectively, and so on. Facilitating discourse refers to teachers facilitating the activities of learners as they agree or disagree and seek to reach consensus. Teachers facilitate discourse by encouraging, acknowledging, or reinforcing students' contributions; setting a positive climate for learning; drawing in participants; prompting discussions; and assessing the efficacy of the process. Direct instruction refers instructors presenting content or questions, confirming understanding through assessment and exploratory feedback, diagnosing misconceptions, and so on (Anderson et al., 2001).

\section{Background}

Following Garrison, Anderson, and Archer's (2010) statement, the CoI framework is still in need of further elaboration since it is a developmental model and has areas of incompleteness, especially with regard to cognitive presence. Earlier studies indicated that cognitive presence is likely the most challenging to study (Akyol, 2009) and develop in online courses among the three components of the $\mathrm{CoI}$ framework since it is a cyclical form of practical inquiry in which learners move deliberately from understanding the problem or issue to exploration, integration, and application (Garrison \& Arbaugh, 2007), and students often face great difficulty arriving at a resolution (Garrison, Anderson, \& Archer, 2001; McKlin, Harmon, Evans, \& Jones, 2002; Vaughan \& Garrison, 2005). Regarding social presence, the literature indicates that it is essential to establish a CoI (Garrison et al., 2000) as it has an impact on learning due to social interaction (Richardson \& Swan, 2003; Swan \& Shih, 2005; Tu \& McIsaac, 2002). It is significantly related with and a predictor of cognitive presence (Akyol, 2009; Kozan \& Richardson, 2014; Rourke, Anderson, Garrison, \& Archer, 1999). Therefore social presence is of value and still requires more attention due to its importance (Garrison \& Arbaugh, 2007).

Respecting teaching presence, previous research concludes that teaching presence is the most known element in the CoI framework. It functions as a mediating role and must be available in order to evolve from social presence into cognitive presence (Akyol, 2009; Garrison 
\& Cleveland-Inness, 2005; Kozan \& Richardson (2014). The current study examined students' social presence, cognitive presence, and teaching presence within an online asynchronous discussion setting by describing their posting behaviors relative to these three constructs.

\section{Methods}

This research adopts an instrumental case study design in which "a researcher is interested in understanding something more than just a particular case, and the researcher is interested in studying the particular case only as a means to some larger goal" (Fraenkel, Wallen, \& Hyun, 2012, p. 435). This study was conducted within an Information and Communication Technology-I course offered online by the Department of Informatics at a large public university. The two-credit course is compulsory for all students. It lasts 16 weeks, with 100 minutes of synchronous session each week. The course aims to teach the fundamentals of computer literacy based on the European Computer Driving License (ECDL) and helps students gain competency in basic office software. The course is taught fully online through Adobe Connect and is supported with Moodle as the learning management system (LMS) and a Facebook page for the instructor's and students' use. The instructor used direct instruction, demonstration, drill and practice, and problem-based learning instructional methods. The first author was included in both Moodle and the course Facebook page with the course instructor's authorization, indicating full of authority in management of the online platforms. All course materials and course sessions in video format were shared on Moodle for nonparticipants. Assessment of students' performances was conducted using both formative and summative assessment.

\section{Participants}

Purposive sampling was used for this study. Students, who had prior experience in online learning and also were enrolled in a fully online degree program in the Department of Medical Documentary and Secretary (MDS) at a well-known public university, were selected purposively. Among the 162 students who enrolled in the program, 91 students who participated in most of the six discussion activities in the course were selected for the study. The number of students in each discussion activity (DA) is provided in Table 1.

Table 1

Number of Students in Discussion Activities

\begin{tabular}{lc}
\hline Discussion activity (DA) & Number of students \\
\hline DA1 & 73 \\
DA2 & 70 \\
DA3 & 62 \\
DA4 & 64 \\
DA5 & 60 \\
DA6 & 62 \\
Participating students & 91 \\
No participation & 71 \\
Class size & 162 \\
\hline
\end{tabular}

The average number of students who participated in each DA was 65 . The minimum number of students was 60 , and the maximum number was 73 in the six discussion activities. 


\section{Data Collection Instrument and Procedure}

Asynchronous discussion postings of students were used to identify indicators for social presence, cognitive presence, and teaching presence. Discussion questions were developed based on course content, and required students to articulate their own ideas and interpretations and then think reflectively. The discussion questions were checked by the instructor of the course and the researchers to assure content validity, understandability, and appropriateness for the students, content, and context. The questions aimed to facilitate students' cognitive presence and social presence. In two discussion activities, the questions aimed to facilitate teaching presence. The questions were in open-ended format. Each week, students discussed two questions and offered their ideas, knowledge, and feelings accordingly.

The first discussion activity (DA1) included students' first experiences in using computers, the difficulties and/or problems they faced, and how they overcame those difficulties. In addition, they were asked about their views on computers being beneficial in their daily life, their strategies and skills in handling information pollution, their suggestions to overcome this problem, and their justification of their solutions. The second discussion activity (DA2) focused on excessive use of social networking services and the reasons behind it. Plagiarism and unethical use of any information on the Internet, their own experience with plagiarism, and suggestions and solutions to handle this problem were also included. The third discussion activity (DA3) concerned the students' experience when learning something new on the computer, problems they faced, and how they solved those problems. Students were also asked about how they benefitted from their friends and from the Internet in addition to the group activities, and the various benefits and drawbacks of each of these. The fourth discussion activity (DA4) targeted the safety of digital information and potential ways either individual or mass users (e.g., public organizations, universities, legislative regulations) addressed the safety of usage and protection. Students' experiences with word processing software were also discussed, as well as the problems they faced and their solutions. The fifth discussion activity (DA5) dealt with online search strategies and step-by-step solutions for assigned problems on the Internet. Moreover, students were asked about the course instructor's efforts, behaviors, and teaching style, as well as the course, design, organization, discourse, and instruction. Students also made suggestions to overcome identified problems and improve the course. Finally, the sixth discussion activity (DA6) examined the students' sense of community, communication and interaction with the course instructor and their classmates, their likelihood to integrate course content into real life, and their impressions of Moodle and the course page on Facebook.

Each discussion was open for two weeks and held asynchronously on Moodle, the course management system. Data collection started during the second week of the semester and was completed in 12 weeks. The instructor served as facilitator and the researchers as observers during this process.

\section{Data Analysis}

Students' posts were analyzed through qualitative and quantitative data analysis methods. Both descriptive and transcript analysis were conducted. For descriptive analysis, the number of all discussion posts in each activity was investigated to determine whether or not it contained any indicator of social presence, cognitive presence, and teaching presence together or separately. The percentages were calculated based on the total number of students that participated in each activity divided by the number of posts containing any indicator of the categories of social presence, cognitive presence, and teaching presence. Transcript analysis of discussion postings was conducted deductively based on the coding matrix provided by the developers of the CoI framework. The data were coded in accordance with the categories of 
social presence, cognitive presence, and teaching presence, and in the analysis, students' posts could be included in one or more categories at the same time.

\section{Trustworthiness}

Objectivity of transcription analysis of coding discussions was ensured using the interrater-agreement method. The posts were analyzed by the researcher and another rater separately to ensure accuracy and validate the findings. In the interrater agreement process with regard to social presence, 40 students' posts in DA1 were coded based on its three categories: affective/personal, open communication, and group cohesion. The results yielded an $80.4 \%$ agreement (Cohen, 1960), which shows substantial agreement. Moreover, Kappa value was also calculated. This is a better approach, which calculates the measure of agreement while taking into account random agreement opportunities (Altman, 1999; Landis \& Koch, 1977). Since the data were qualitative, and coding was based on categorical, nominal codes, Cohen's kappa $(\kappa)$ was used to detect the level of agreement. According to the result, there was a substantial (good) agreement between the two raters' judgments, $\kappa=.715, p<.05$. Both methods indicate a good level of agreement between the raters in the coding of discussion posts based on social presence.

Corresponding to the interrater agreement process for cognitive presence, 40 students' posts in DA1 were coded based on its four categories: triggering event, exploration, integration, and resolution. The level of agreement was $91.8 \%$, which indicates coding of discussion posts was conducted with an almost perfect level of agreement, eliminating subjectivity of the researcher (Cohen, 1960). Another, more accurate measure, Cohen's kappa, was also calculated and yielded substantial agreement between the two raters' judgments, $\kappa=.892, p<.05$.

With regard to the interrater agreement process for teaching presence, 40 students' posts in DA5 were coded for its three-categories: design and organization, facilitating discourse, and direct instruction. The percentage of agreement indicated almost perfect agreement $(83.1 \%)$ between the two coders (Cohen, 1960). Similarly, Cohen's kappa yielded substantial agreement between the two raters' judgments, $\kappa=.736, p<.05$.

\section{Results}

Students' posting patterns were analyzed deductively based on a coding matrix. For each DA, Table 2 presents a summary of descriptive information to provide a general viewpoint for all the discussion activities and the students' participation ratio.

Table 2

Summary of Discussion Posts in Online Asynchronous Discussion Activities

\begin{tabular}{lrrrrrrr}
\hline & DA1 & DA2 & DA3 & DA4 & DA5 & DA6 & Average \\
\hline Number of students & 73 & 70 & 62 & 64 & 60 & 62 & 65 \\
$\begin{array}{l}\text { Number of } \\
\text { sentences }\end{array}$ & 555 & 640 & 448 & 461 & 346 & 501 & 492 \\
$\begin{array}{l}\text { Average number of } \\
\text { sentences }\end{array}$ & 8 & 9 & 7 & 7 & 6 & 8 & 8 \\
$\begin{array}{l}\text { Number of words } \\
\begin{array}{l}\text { Average number of } \\
\text { words }\end{array}\end{array}$ & 7,183 & 8,302 & 6,079 & 5,299 & 4,402 & 6,271 & 6,256 \\
\hline
\end{tabular}


The number of students participating in discussions differed for each activity. From a total of 162 students in the class, 91 students $(56 \%)$ participated in discussions. The minimum number of participating students was 60 , while the maximum was 73 . The total number of sentences also varied. Students wrote the most for DA2 and the least for DA5. Details of posts for each presence are provided separately in the following subsections.

\section{Social Presence}

Percentage values were calculated from the total number of students that participated in each DA divided by the number of posts containing any indicator of the categories of social presence - namely, affective/personal, open communication, and group cohesion. The result is presented in Table 3. There were no indicators of social presence in two of the students' posts in DA2 and in DA6.

Table 3

Coding Result of Social Presence

\begin{tabular}{lccc}
\hline & Affective/personal & Open communication & Group cohesion \\
\hline DA1 & $95 \%$ & $47 \%$ & $29 \%$ \\
DA2 & $80 \%$ & $87 \%$ & $53 \%$ \\
DA3 & $76 \%$ & $89 \%$ & $66 \%$ \\
DA4 & $98 \%$ & $41 \%$ & $38 \%$ \\
DA5 & $82 \%$ & $88 \%$ & $35 \%$ \\
DA6 & $95 \%$ & $90 \%$ & $60 \%$ \\
Average & $87 \%$ & $73 \%$ & $47 \%$ \\
\hline
\end{tabular}

As provided in Table 3, students' posts in regard to social presence reflected mostly affective/personal (87\%), followed by open communication (73\%), and then group cohesion $(47 \%)$ categories. The sharpest increase occurred in open communication in the second and the fifth activities, whereas the sharpest decrease was seen in DA4 for open communication and group cohesion. Students' posting behaviors are also presented graphically in Figure 1, which shows the indicators in their discussion posts. It is explicit that the highest reflected category overall was affective/personal while the least reflected category overall was group cohesion. It can be inferred that students generally responded individually more than collaboratively. An example of the indicator of affective/personal expressions from the students' discussion posts is the following:

It is not possible to be bored in this class because the instructor teaches the course very well and makes us active, although ICT-I course is an online course. She is interested with our problems and repeats and explains insistently what we initially did not understand. The course is designed so well that I cannot see any deficiency (smiling). (DA5, Student 13)

In addition, in three activities (DA1, DA4, and DA6), the affective/personal indicator was at the highest level, while in the other three (DA2, DA3, and DA5) open communication was at the highest level. A sample student post indicating open communication is this: "I like this course since I overcame my deficiencies and enhanced my knowledge with the help of this course. Our instructor planned and designed the course very well. Thanks to our instructor and for her effort" (DA5, Student 16). 
Group cohesion behaviors enhanced up to the midpoint and then decreased sharply. Open communication and group cohesion behaviors indicated similar patterns based on looking solely at the beginning and endpoint of the Das. Group cohesion behaviors increased at the midpoint and slightly decreased at the endpoint. Two samples from students' posts indicating group cohesion are as follows: "Thank you very much, teacher. Thanks for your effort!" (DA6, Student 20), and "Everything is excellent. Thank you teacher!" (DA5, Student 57). Overall, in students' discussion posts, the affective/personal indicator was the highest while the group cohesion indicator was the lowest throughout the whole period.

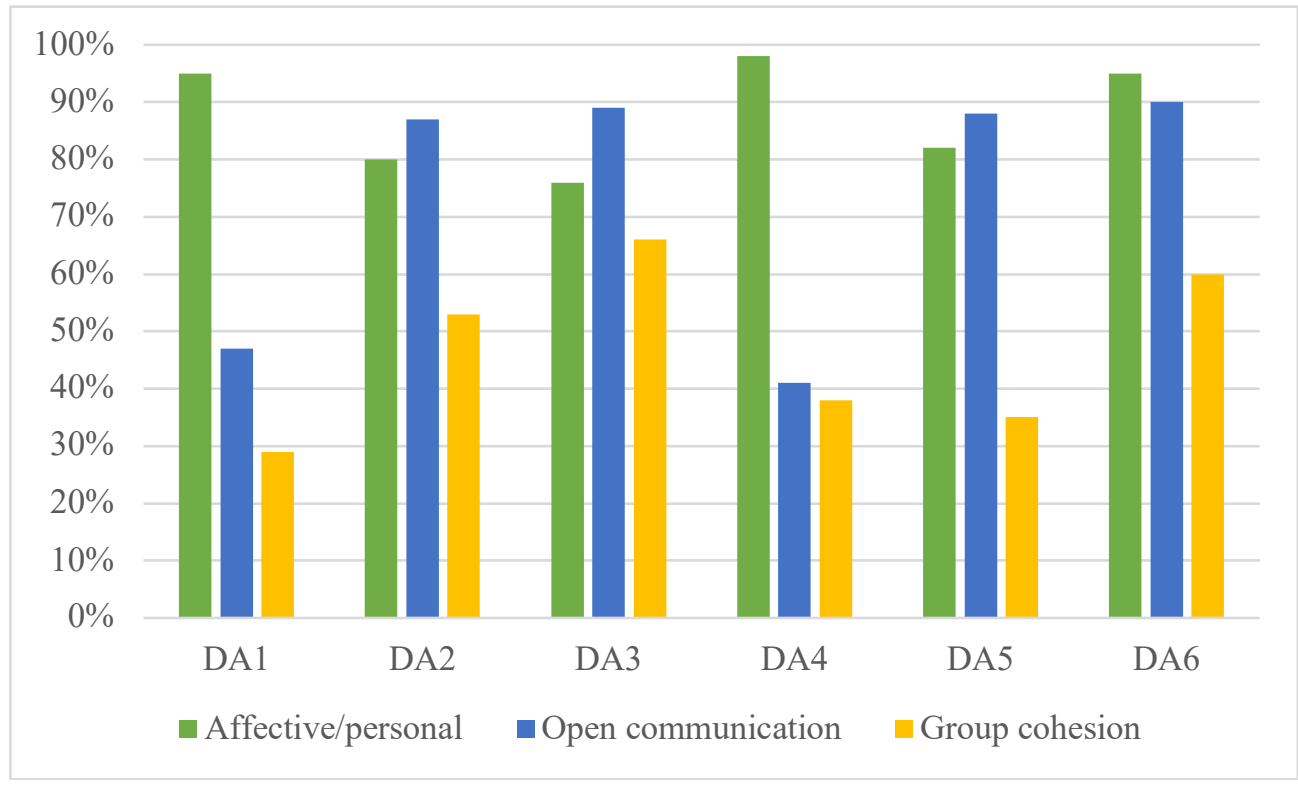

Figure 1. Coding result for social presence.

\section{Cognitive Presence}

Students' posts were examined for the four categories of cognitive presence, which are triggering event, exploration, integration, and resolution. The coding results are presented in Table 4. Two posts, one in DA2 and the other in DA6, were not suitable for any of the categories.

Table 4

Coding Result for Cognitive Presence

\begin{tabular}{lcccc}
\hline & Triggering event & Exploration & Integration & Resolution \\
\hline DA1 & $67 \%$ & $90 \%$ & $52 \%$ & $51 \%$ \\
DA2 & $39 \%$ & $34 \%$ & $14 \%$ & $27 \%$ \\
DA3 & $77 \%$ & $95 \%$ & $16 \%$ & $55 \%$ \\
DA4 & $77 \%$ & $92 \%$ & $42 \%$ & $45 \%$ \\
DA5 & $20 \%$ & $98 \%$ & $67 \%$ & $27 \%$ \\
DA6 & $48 \%$ & $23 \%$ & $16 \%$ & $89 \%$ \\
Average & $55 \%$ & $72 \%$ & $35 \%$ & $49 \%$ \\
\hline
\end{tabular}

The findings shown in Table 4 indicated that students' posts reflected exploration (72\%) the most and integration (35\%) the least. The posts reflected triggering event $(55 \%)$ and resolution (49\%) at average levels. It can be inferred from the findings that overall indicators of exploration were twice that of integration. Both the most remarkable increase and decrease occurred in exploration, in DA3 and DA6, respectively. There was a sharp decrease again in exploration in DA2. Considering striking enhancement, they were also seen in the categories 
of triggering event, integration, and resolution. In DA3, a remarkable improvement occurred in triggering event, similar to integration in DA4, and the case of resolution in both DA3 and DA6. On the other hand, there was an outstanding decrease across categories except for the resolution category, and there was a salient decrease in all four categories for DA2. An outstanding decline was also seen in DA5 in both triggering event and resolution. Furthermore, in DA6 a noticeable decrease occurred in both exploration and integration.

Figure 2 indicates the changes graphically. The graphic indicates that students mostly tried to explore the content, appreciate the diverse perspectives, explore the content collaboratively, and so on. The following is an example of the indicator of exploration in students' discussion posts:

Some of them try to use social media to communicate while some do not, but they are only a waste of time. Even though they are in our lives, people forgot about having a heart-to-heart talk or even saying Hello in real life. This is a bitter experience... With each passing day, social media platforms used for communication are pulling people inside themselves subconsciously. This addiction can cause psychological illnesses beyond addiction. Caution is in fact inside oneself. If they know the usage reasons of those platforms and use them consciously, then precautions could be taken. However, for those that cannot prevent this addiction we need to direct them to psychological therapy centers, like in the USA; we could organize conferences about the disadvantages of virtual communication and social media usage or some activities that could be done for those to direct them into real communications beyond virtual ones. (DA2, Student 18)

Additionally, the results gave hints as to the lack of sustained critical reflection, connecting ideas and synthesis, and so on. Triggering event declined after DA1 but increased sharply at the midpoint. For instance, one student posted, "I wondered about it and in essence, fiddling about with the computer provided me the opportunity to learn and satisfy my own curiosity" (DA1, Student 27).

Indicators of integration were generally low, except for two activities. A sample of the indicator of integration from the students' posts is the following

Information retrieved from the Internet is not always correct; for this very reason, I always check its correctness from at least three websites and if it does not persuade me, then I look for official webpages; and if it is still not enough, then I look for the main source of the information that I found on the Internet, searching for the books and through encyclopedias. The Internet provides easy access to something, but its correctness is always questionable. (DA1, Student 29)

At the endpoint, resolution was strikingly enhanced. A sample student's post in resolution is below:

As I learned on the Math course, to solve a problem, first you should know the formula and do the required steps in order; like first multiplication and division, and then addition and subtraction in a math problem. For this reason, first I determine the required steps, and the order of the steps is important for me; then I do each step in order to solve a problem... And, the solution accepted by myself comes to the end. (DA5, Student 59) 


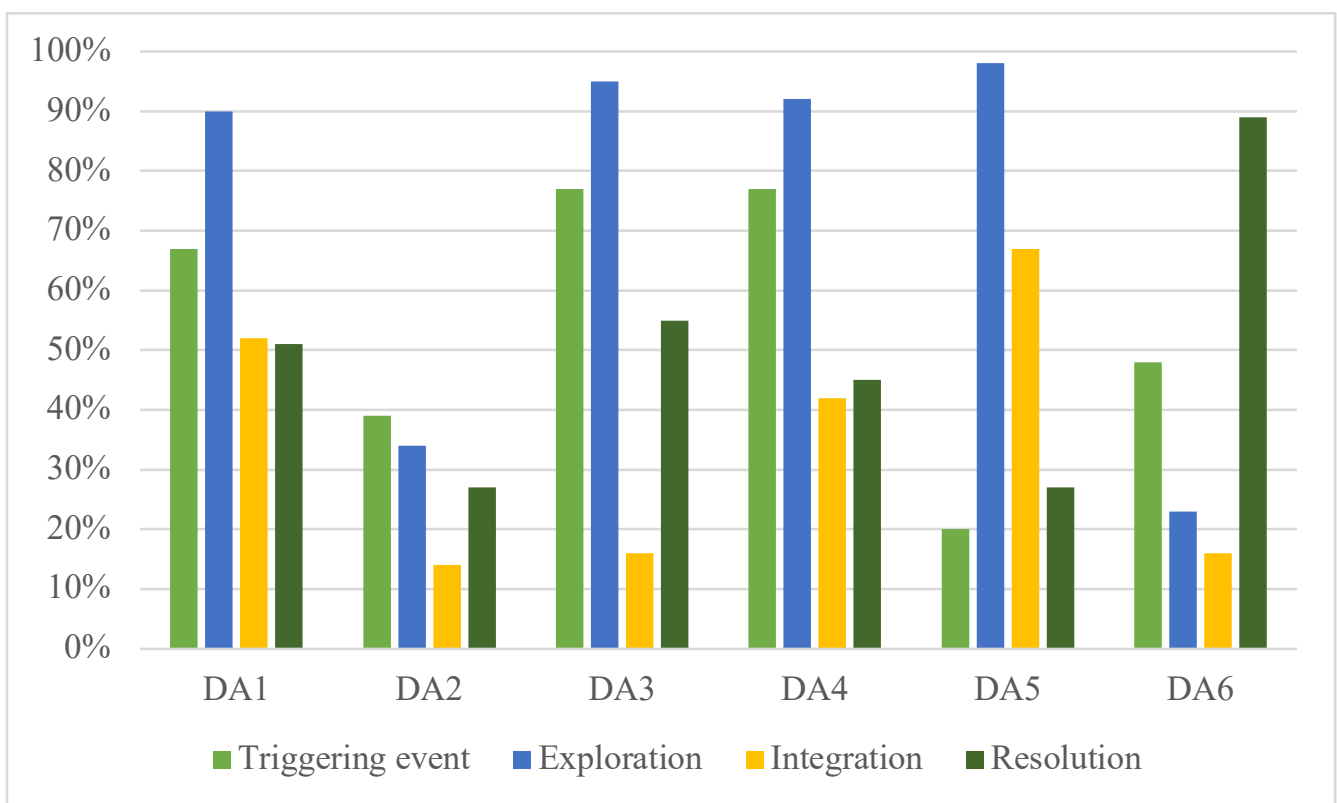

Figure 2. Coding result in cognitive presence.

\section{Teaching Presence}

Students' posts in teaching presence were examined based on its three categoriesnamely, design and organization, facilitating discourse, and direct instruction. The findings are visualized in Figure 4. Students' posts in two discussion activities from highest to lowest were design and organization (84\%), followed by direct instruction (65\%), and then facilitating discourse $(50 \%)$. The focus of their posts was on the design and organization of the course, flow of the course, and appropriateness of course methods and activities. For instance, one student posted the following:

I like the design and organization of the course since my instructor teaches the course, emphasizing the practice... I learn something new in each course. Then, I practice it immediately in order to repeat and not to forget it. The course is so welldesigned that I think there is no deficiency. (DA5, Student 2)

Their posts about both design and organization, and facilitating discourse increased in DA6, in contrast to direct instruction. Indicators of facilitating discourse were the lowest, although they increased in DA6 (see Figure 3). A sample student's post that reflect facilitating discourse is the following:

I like [the instructor's] teaching style, you use a simple language. When you teach any subject, it captures my attention and I can easily listen to you... You encourage us to brainstorm in this way. I feel myself like I am in formal education. (DA5, Student 6)

Regarding the indicator of direct instruction in students' discussion posts, the level was $65 \%$, although it declined in the sixth discussion activity. Still, it was at an adequate level. Following is a sample student's post of the indicator of direct instruction:

Our instructor teaches the course with details of the topics and in a way that I can understand. This increases my motivation. Also, I am not shy in asking questions. She explains and repeats what we didn't understand again and again. (DA5, Student 10) 


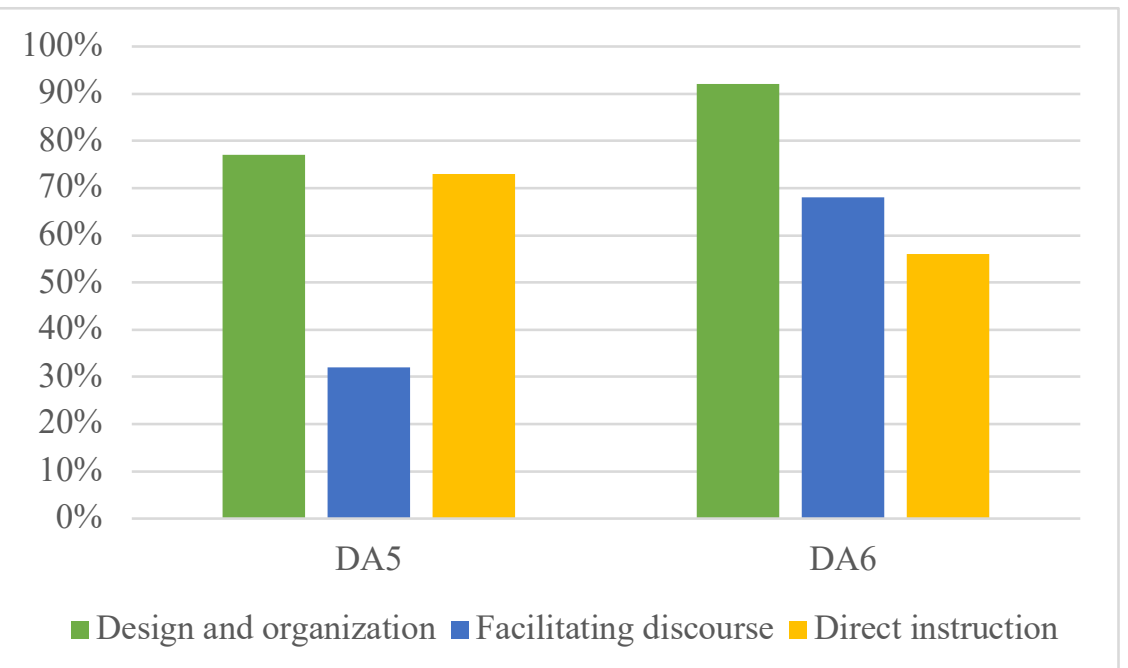

Figure 3. Coding result in teaching presence.

\section{Discussion and Conclusion}

The findings were discussed and concluded separately in respect to social presence, cognitive presence, and teaching presence.

\section{Social Presence}

This study found a higher level of social presence when compared to earlier research (Akyol, 2009; Kim, 2015). In this case study, the reason for high levels of open communication and group cohesion could be usage of the Facebook group and/or the WhatsApp group. Many students declared in some activities that both Facebook and WhatsApp contributed to their interaction and communication with the rest of the class. They were informed and kept up to date for any activity, announcement, reminder, call for participation, and any other important information. The positive influence of social networking sites (SNS) - specifically Facebookon social presence was also found in a more recent study by Lim and Richardson (2016). In addition, this situation might be explained by cultural differences. The effect of culture in using SNS in daily life was addressed in some earlier studies (e.g., Chau, Cole, Massey, MontoyaWeiss, \& O'Keefe, 2002; Jackson, \& Wang, 2013; Qui, Lin, \& Leung, 2013). Some differences could also be expected in teaching-learning environments. For example, a recent study concluded that although Turkish instructors anticipated SNS as an information-sharing and socialization platform, Germans were more optimistic about benefits such as discussion, communication, information, and material sharing (Kilis, Rapp, \& Gülbahar, 2014). Another recent study investigating students' involvement and acceptance of Facebook as a course management system concluded that Facebook outperformed Moodle in many respects, including increased communication and interaction among students and instructors, larger number of discussion posts, better facilitating conditions, greater number of involved discussions and higher perceived usefulness, increased behavioral intention to use, greater number of comments, enhanced facilitation of getting timely feedback, and so on (Albayrak \& Yildirim, 2015).

In this current study, similar to Albayrak and Yildirim (2015), students favored Facebook over Moodle, which could be also a consequence of the culture itself, with the everincreasing number of people using Facebook in the country. Also, when compared to Moodle, which is a less user-friendly environment, Facebook could be expected to be favored by the students. This might improve students' social presence (Kilis \& Yildirim, 2018). The other issue is that some previous empirical findings indicated that Facebook is an effective discussion 
environment in online and/or blended learning (English \& Duncan-Howell, 2008; Mazer, Murphy, \& Simonds, 2007). Since it facilitates communication, interaction, and cooperation, it has favorable effects on social presence and the sense of community (Mazer et al., 2007; Schroeder, Minocha, \& Schneider, 2010). Another study indicated the enhancement of social presence using Twitter, which facilitated free-flowing "of-the-moment" interactions and social connections (Dunlap \& Lowenthal, 2009). Considering these points, with the lack of practical studies based upon effective theoretical and pedagogical orientations, Öztürk (2015) examined whether Facebook suited the CoI framework. She concluded that because of the high level of student presence Facebook is a suitable online learning environment for the CoI framework, with features that foster critical thinking, discussion, cooperation, and learning besides the more obvious benefits for social relations. This study corroborates the results of prior studies in the same way through exploring the positive effect of Facebook on students' social presence.

Furthermore, a high level of social presence could be reasoned to have been the result of students' own efforts, self-regulation, presence in a warm and comfortable learning environment, the instructor's effort and guidance, or even students' own innate characteristics. Earlier studies generally studied graduate students, who may already be more self-regulated but may be less socialized. However, it can be inferred that both students and instructors had positive contributions in the development of students' social presence. The discussion activities indicated that students favored the kindness behaviors of their instructor and their classmates during the semester. The instructor might contribute students' self-expression and selfdisclosure as well as sense of belonging to the community through kind behaviors. They can facilitate students' contributions, encourage them to ask their questions and to feel comfortable both during the course and outside class hours. In the same way, kind behaviors of classmates might affect sense of belonging to the community, communication, and collaborative work during and outside of the class and, therefore, might positively influence social presence.

Overall, the indicators of social presence in students' posts were high in this study. More specifically, affective/personal behaviors were high at the beginning and maintained throughout the treatment process. Open communication and group cohesion were developed during the semester thanks to the structured discussion activities, the course Facebook page, and course topics addressing real life, as well as focusing on self-disclosure of students rather than pure information and facts. Students favored their instructor's and classmates' kind behaviors. The students initiated a group on WhatsApp for the purposes of collaboration and cooperation to make working with each other easy in the collaborative learning community. The large class size (162 students) could be overwhelming for some, but most students favored the instructor's effort and guidance. However, some students mentioned facing challenges during the course, such as marital status, having children, difficult working conditions, technical and usability problems with Moodle, and individual assignments.

\section{Cognitive Presence}

Considering the needs indicated in earlier studies, particularly on cognitive presence, this study focused notably on cognitive presence. The results revealed a substantial level of cognitive presence, contrary to prior research (Akyol, 2009; Akyol \& Garrison, 2011; Kim, 2015; Tik, 2016). In the aforementioned studies, it was claimed that synchronous online discussions constituted a time barrier to reach the resolution phase. To overcome this barrier, this study designed online discussions asynchronously to fully understand the actual constitutions and improvement of cognitive presence. This resulted in significant development across all four categories and also sustained cognitive presence at high or fair levels, contrary to the other studies. These findings could be the result of design and organization of the discussions, as well as a level of attractiveness of the topics covered. The topics were selected based on real-life situations to stimulate brainstorming and critical thinking in addition to 
inspiring the use of students' own experiences rather than relying on pure information and facts. More importantly, besides triggering their curiosity, interest, and motivation, the topics covered provided an opportunity to explore the tasks, appreciate diverse perspectives, create solutions, and apply solutions to their life. Students were encouraged to share their own experiences, reflect on them and develop new or deeper knowledge. Therefore, the design and context of the discussion activities were of paramount importance for the improvement seen in students' cognitive presence. It was noted in a few recent studies (e.g., Redmond, 2014) that when online discussions were structured appropriately, students could share and document their own thinking and reflect on both their own and other students' contributions. When asked to reflect on their learning experience with a given scenario, students could apply their new knowledge more easily and resolve the issue, which means they could reach the resolution phase.

Another recent study (Liu \& Yang, 2014) reached similar conclusions as this current study, stating that discussion types and context affect students' cognitive presence and recommended that real-life experiences should be covered in discussions in order to enhance cognitive presence. This current study was specifically designed to invoke discussions focusing on the dimensions of cognitive presence and, thus, succeeded with a high level of cognitive presence, and even saw half of the student's progress right through to reaching the resolution phase. Through these findings, researchers of this current study have come to appreciate the importance of real-life experiences, such as assigned cases and scenarios, covered in online discussions. Moreover, the discussion questions were designed in accordance with problembased learning approach.

Overall, this study was found to be in agreement with both Redmond's (2014) and Liu and Yang's (2014) statements, and enhanced the understanding of cognitive presence with a more complete exploration by indicating the ways to attain, improve, and sustain a high level of cognitive presence in the nature of online learning. Therefore, online instructors and educators should be aware that students are able to reach all four phases of cognitive presence, and they should set appropriate course activities to guide students and foster their ability to challenge themselves through the process of critical thinking (Giannousi \& Kioumourtzoglou, 2016; Ladyshewsky, 2013). Thus, it is highly recommended to design discussion activities based on real-life experiences and provide scenarios for discussion activities rather than pure factual information. It would also be better to design activities based on the problem-based learning approach to enhance students' reflections and critical thinking and help them construct new knowledge or deepen their existing knowledge.

Another issue behind a high level of cognitive presence is cooperation among students. Many students placed significant emphasis on cooperation to foster their cognitive presence. Collaboration is already a part of the basis of the CoI framework. Although these two concepts, collaboration and cooperation, are not the same, they are close to each other to some extent, and support students' experiences in cognitive ability. Cooperation could therefore improve students' cognitive presence by encouraging brainstorming or exploration and interaction. Therefore, with regard to designing a collaborative learning community, it could be better for online instructors to take cooperation into consideration in addition to collaboration both inclass and out-of-class, and also when designing course activities.

The other issue related to the high level and improvement of cognitive presence was sustaining motivation. Holding asynchronous discussion in a large class of 162 students without forming small groups is not an easy task. However, in the case of the class of the current study, it was deemed successful after providing and maintaining a high level of cognitive presence. In a recent study, Kim (2015) stated that choosing attractive topics for students and addressing real-life cases could lead to a high level of cognitive presence. In the current study, students were willing and motivated through the application of regular activities. Also, the questions 
were not seen as boring for the students, and they could easily express their own experiences and conduct brainstorming with their classmates. This case study provides more elaboration on cognitive presence and how it can be facilitated. This current study also contributes to the literature that indicates that students can in fact reach the resolution phase, and this could be developed further, as opposed to earlier studies in which difficulty was found at the lowest level (Akyol, 2009; Akyol \& Garrison, 2011) or where students completely failed (Tik, 2016).

In summary, the indicators of cognitive presence in students' discussion posts were at a fairly substantial level in this study. Although earlier studies stated that reaching the resolution phase was very difficult or even did not occur in their study, this current research had students that in fact did reach the resolution phase. The students emphasized the importance of addressing real-life topics and assigning cases or scenarios in discussion activities. Therefore, the researchers of this current study accept the recommendations of both Redmond (2014) and Liu and Yang (2014).

\section{Teaching Presence}

Earlier studies contended that teaching presence was the most known element; therefore, this current study was solely comprised of two activities. It resulted in a substantially or fairly high level of teaching presence, and it succeeded in its significant development during the treatment process, contrary to some earlier studies (e.g., Akyol, 2009; Kim, 2015). Teaching presence was developed especially with the aids of regular discussion activities, and immediate feedback from the course instructor to students. Encouraging students' contributions, reinforcing participation and collaboration, giving instant feedback, and addressing their misconceptions, as well as providing a comfortable learning environment were the reasons behind establishing and sustaining a substantial level of teaching presence. The benefits of using SNS, specifically a Facebook group page, were proven, which is similar to the study of Lim and Richardson (2016). In order to have a better understanding about the effect of instant feedback, further elaboration on a theoretical and pedagogical basis is highly recommended. Still, it indicates the most important factors that have an influence on teaching presence. Further research could focus on the benefits of SNS and instant feedback in order to contribute to the elaboration and improvement of teaching presence.

\section{Implications and Recommendations}

The findings highlighted the importance of designing course and discussion activities that address real-life cases and scenarios in a reflective and attractive way for students. Rather than relying on pure fact-based information in discussions, they can be designed on problembased learning and reflective thinking. Moreover, a comfortable and friendly environment like Facebook or other suitable SNS could be used to facilitate communication, interaction, collaboration, and the feeling of a sense of community. Therefore, SNS has some contribution to make to social presence, cognitive presence, and teaching presence, and further research could look into its application. On the other hand, course management systems - in this case Moodle - could be utilized more and usability problems could be addressed to remove unnecessary distractions. According to Yildirim, Reigeluth, Kwon, Kageto, and Shao (2014), instructors should provide collaborative learning opportunities both inside and outside the classroom, allow for more easy-to-use customizations in the instruction in accordance with learner characteristics, address personalized assessment, include progress tracking and reporting, and demonstrate a responsiveness to learner needs. Thus, an ideal system to meet the standards and required functions in this information age could be developed and further practiced.

In addition, providing timely feedback both in and outside of class is so important in the online learning setting (Akyol, 2009; Shea, Li, Swan, \& Pickett, 2005; Sheridan \& Kelly, 2010) 
to ensure that students are more motivated and interested in the tasks, to address their misunderstandings, to prevent them from getting lost, and to fill their need for a real-time (physical) instructor. Therefore, instant feedback and immediate responsiveness to students' needs, as in this current study, could support learners' social presence and cognitive presence and, consequently, could be subjected to further studies. Finally, kind behaviors of the course instructor, use of simple and easy to understand language, and responsiveness are important factors, particularly for social presence and teaching presence. An instructor's attitude toward their students and awareness of students' overexertion could play an important role in their sense of community. As a concluding remark, further research could concentrate on synchronous online discussion, including instruction in both online and blended learning settings.

A few potential limitations of this study need consideration. First, in this study, discussions were asynchronous; however, in a synchronous format, the results could differ, especially for social presence and, therefore, this could be seen as one of the study's limitations. Second, the instructor was not an active participant in discussion activities, but rather was merely facilitator and observer. If the instructor were an active participant during discussion activities, the results could differ. Hence, this might also be considered as a limitation. Further research could concentrate on online discussion in which the instructor participates actively.

\section{Acknowledgements}

This research did not receive any specific grant from funding agencies in the public, commercial, or not-for-profit sectors. This research was conducted in the scope of a doctoral dissertation study of Selcan Kilis. 


\section{References}

Akyol, Z. (2009). Examining teaching presence, social presence, cognitive presence, satisfaction and learning in online and blended course contexts (Unpublished doctoral dissertation). The Graduate School of Natural and Applied Sciences of Middle East Technical University, Ankara, Turkey.

Akyol, Z., \& Garrison, D. R. (2011). Understanding cognitive presence in an online and blended community of inquiry: Assessing outcomes and processes for deep approaches to learning. British Journal of Educational Technology, 42(2), 233-250.

Albayrak, D., \& Yildirim, Z. (2015). Using social networking sites for teaching and learning: Students' involvement in and acceptance of Facebook ${ }^{\circledR}$ as a course management system. Journal of Educational Computing Research, 52(2), 155-179.

Altman, D. G. (1999). Practical statistics for medical research. London: Chapman \& Hall.

Anderson, T., Rourke, L., Garrison, D. R., \& Archer, W. (2001). Assessing teaching presence in computer conferencing context. Journal of Asynchronous Learning Networks, 5(2), $1-17$.

Chau, P. Y. K., Cole, M., Massey, A. P., Montoya-Weiss, M., \& O’Keefe, R. M. (2002). Cultural differences in the online behavior of consumers. Communications of the $A C M, 45(10), 138-143$.

Cohen, J. (1960). A coefficient of agreement for nominal scales. Educational and Psychological Measurement, 20(1), 37-46.

Dunlap, J. C., \& Lowenthal, P. R. (2009). Tweeting the night away: Using Twitter to enhance social presence. Journal of Information Systems Education, 20(2), 129-136.

English, R. M., \& Duncan-Howell, J. A. (2008). Facebook goes to college: Using social networking tools to support students undertaking teaching practicum. Journal of Online Learning and Teaching, 4(4), 596-601.

Fraenkel, J. R., Wallen, N. E., \& Hyun, H. H. (2012). How to design and evaluate research in education (8th ed.). New York: McGraw-Hill.

Garrison, D. R., \& Akyol, Z. (2015). Toward the development of a metacognition construct for communities of inquiry. The Internet and Higher Education, 24, 66-71.

Garrison, D. R., \& Anderson, T. (2003). E-Learning in the 21st century: A framework for research and practice. London: Routledge/Falmer.

Garrison, D. R., Anderson, T., \& Archer, W. (2000). Critical inquiry in a text-based environment: Computer conferencing in higher education. The Internet and Higher Education, 2(2-3), 87-105.

Garrison, D. R., Anderson, T., \& Archer, W. (2001). Critical thinking and computer conferencing: A model and tool to assess cognitive presence. American Journal of Distance Education, 15(1), 7-23.

Garrison, D. R., Anderson, T., \& Archer, W. (2010). The first decade of the Community of Inquiry framework: A retrospective. The Internet and Higher Education, 13(1-2), 5-9.

Garrison, D. R., \& Arbaugh, J. B. (2007). Researching the Community of Inquiry framework: Review, issues, and future directions. The Internet and Higher Education, 10(10), $157-172$. 
Garrison, D. R., \& Cleveland-Innes, M. (2005). Facilitating cognitive presence in online learning: Interaction is not enough. American Journal of Distance Education, 19(3), 133-148.

Garrison, D. R., Cleveland-Innes, M., \& Fung, T. S. (2010). Exploring causal relationships among teaching, cognitive and social presence: Student perceptions of the Community of Inquiry framework. The Internet and Higher Education, 13(1), 31-36.

Giannousi, M., \& Kioumourtzoglou, E. (2016). Cognitive, social, and teaching presence as predictors of students' satisfaction in distance learning. Mediterranean Journal of Social Sciences, 7(2 S1), 439-447.

Jackson, L. A., \& Wang, J. L. (2013). Cultural differences in social networking site use: A comparative study of China and the United States. Computers in Human Behavior, 29(3), 910-921.

Kilis, S., \& Yildirim, Z. (2018). Investigation of Community of Inquiry framework in regard to self-regulation, metacognition and motivation. Computers \& Education, 126, 5364.

Kilis, S., Rapp, C., \& Gülbahar, Y. (2014). Eğitimde sosyal medya kullanımına yönelik yükseköğretim düzeyindeki eğitmenlerin algısı: Türkiye-Almanya örneklemi [Perceptions of instructors about social media usage in higher education: The cases of Turkey and Germany]. Journal of Instructional Technologies \& Teacher Education, $3(3), 20-28$.

Kim, W. (2015). Learning flow, motivation, and community of inquiry in an online graduate degree program (Unpublished doctoral dissertation). The Graduate School of Purdue University, United States.

Kozan, K., \& Richardson, J. C. (2014). Interrelationships between and among social, teaching, and cognitive presence. The Internet and Higher Education, 21, 68-73.

Ladyshewsky, R. K. (2013). Instructor presence in online courses and student satisfaction. International Journal for the Scholarship of Teaching and Learning, 7(1), Art. 13.

Landis, J. R., \& Koch, G. G. (1977). The measurement of observer agreement for categorical data. Biometrics, 33(1), 159-174.

Lim, J., \& Richardson, J. C. (2016). Exploring the effects of students' social networking experience on social presence and perceptions of using SNSs for educational purposes. The Internet and Higher Education, 29, 31-39.

Liu, C. J., \& Yang, S. C. (2014). Using the Community of Inquiry model to investigate students' knowledge construction in asynchronous online discussions. Journal of Educational Computing Research, 51(3), 327-354.

Mazer, J. P., Murphy, R. E., \& Simonds, C. J. (2007). I'll see you on "Facebook": The effects of computer-mediated teacher self-disclosure on student motivation, affective learning, and classroom climate. Communication Education, 56(1), 1-17.

McKlin, T., Harmon, S. W., Evans, W., \& Jones, M. G. (2002). Cognitive presence in webbased learning: A content analysis of students' online discussions. American Journal of Distance Education, 15(1), 7-23.

Öztürk, E. (2015). Facebook as a new Community of Inquiry environment: An investigation in terms of academic achievement and motivation. Journal of Baltic Science Education, 14(1), 20-33. 
Qiu, L., Lin, H., \& Leung, A. K. Y. (2013). Cultural differences and switching of in-group sharing behavior between an American (Facebook) and a Chinese (Renren) social networking site. Journal of Cross-Cultural Psychology, 44(1), 106-121.

Redmond, P. (2014). Reflection as an indicator of cognitive presence. E-Learning and Digital Media, 11(1), 46-58.

Richardson, J. C., \& Swan, K. (2003). Examining social presence in online courses in relation to students' perceived learning and satisfaction. Journal of Asynchronous Learning Networks, 7(1), 68-88.

Rourke, L., Anderson, T., Garrison, D. R., \& Archer, W. (1999). Assessing social presence in asynchronous, text-based computer conferencing. Journal of Distance Education, 14(3), 51-70.

Schroeder, A., Minocha, S., \& Schneider, C. (2010). The strengths, weaknesses, opportunities and threats of using social software in higher and further education teaching and learning. Journal of Computer Assisted Learning, 26(3), 159-174.

Shea, P., \& Bidjerano, T. (2009). Community of Inquiry as a theoretical framework to foster "epistemic engagement" and "cognitive presence" in online education. Computers \& Education, 52(3), 543-553.

Shea, P., Li, C., Swan, K., \& Pickett, A. (2005). Developing learning community in online asynchronous college courses: The role of teaching presence. Journal of Asynchronous Learning Networks, 9(4), 59-82.

Sheridan, K., \& Kelly, M. (2010). The indicators of instructor presence that are important to students in online courses. MERLOT Journal of Online Learning and Teaching, 6(4), 767-779.

Swan, K., Garrison, D. R., \& Richardson, J. C. (2009). A constructivist approach to online learning: The Community of Inquiry framework. In C. R. Payne (Ed.), Information technology and constructivism in higher education: Progressive learning frameworks (pp. 43-57). Hershey, PA: IGI Global.

Swan, K., \& Shih, L. F. (2005). On the nature and development of social presence in online course discussions. Journal of Asynchronous Learning Networks, 9(3), 115-136.

Tik, C. C. (2016). Community of Inquiry for graduate certificate in higher education. Psychology, 6(1), 24-31.

Tran, T. M. (2011). An examination of cognitive presence and learning outcome in an asynchronous discussion forum (Unpublished doctoral dissertation). College of Education, Georgia State University, United States.

Tu, C. H., \& McIsaac, M. (2002). The relationship of social presence and interaction in online classes. The American Journal of Distance Education, 16(3), 131-150.

Vaughan, N., \& Garrison, D. R. (2005). Creating cognitive presence in a blended faculty development community. The Internet and Higher Education, 8(1), 1-12.

Yildirim, Z., Reigeluth, C.M., Kwon, S., Kageto, Y., \& Shao, Z. (2014). A comparison of learning management systems in a school district: Searching for the ideal personalized integrated educational system (PIES). Interactive Learning Environments, 22(6), 721 736. 